\title{
An Air Operated Domestic Brackish Water Reverse Osmosis Plant: Economically Sustainable Solution for Safe Drinking Water Supply for Chronic Kidney Disease of Unknown Etiology Affected Areas in Sri Lanka
}

\author{
Mudiyanselage Chaminda Priyankara Dissanayake \\ Department of Marine Engineering, General Sir John Kotelawala Defence University, Ratmalana, Sri Lanka \\ Email: dissanayakemcp@kdu.ac.lk
}

How to cite this paper: Dissanayake, M.C.P. (2020) An Air Operated Domestic Brackish Water Reverse Osmosis Plant: Economically Sustainable Solution for Safe Drinking Water Supply for Chronic Kidney Disease of Unknown Etiology Affected Areas in Sri Lanka. Journal of Water Resource and Protection, 12, 911-920.

https://doi.org/10.4236/jwarp.2020.1211053

Received: September 27, 2020

Accepted: November 10, 2020

Published: November 13, 2020

Copyright $\odot 2020$ by author(s) and Scientific Research Publishing Inc. This work is licensed under the Creative Commons Attribution International License (CC BY 4.0).

http://creativecommons.org/licenses/by/4.0/

\begin{abstract}
Chronic Kidney Disease with unknown etiology (CKDu) is one of the crucial health issues in North Central, Uva, North Western, North, Central, and Eastern Provinces of Sri Lanka and incapacitates the kidney function. The main source for the CKDu has not yet been identified, though many scientists believed that the number of certain drinking water quality parameters is changed due to the contamination of water sources by agricultural activities. Hence, the government of Sri Lanka introduces electrically driven Brackish Water Reverse Osmosis (BWRO) plants with a capacity of 10 tones/day to supply safe drinking water for the impacted community though it is an energy-intensive process. Concurrently, a smaller version of an electrically driven BWRO plant was introduced to the rural farming community for their domestic use. However, it was not practically worked out due to various reasons such as high cost, unavailability of electrical power supply for those villages. In this study, an economical air operated domestic use BWRO plant with zero-emission was designed. This anticipated system significantly reduces the government expenditures to subsidize the water purification cost by $50 \%$ of the existing expenses. Besides, simple payback time was found to be 2.5 years, and the benefit-cost ratio to be more than 1 . Evaluating the performance with the conventional values, it comprehends with more sustainable and economically viable system compared to the existing method of water purification.
\end{abstract}

\section{Keywords}

Brackish Water Reverse Osmosis, Membrane, Chronic Kidney with Disease 
Unknown Aetiology, Safe Drinking Water, Sri Lanka

\section{Introduction}

The honored history of Sri Lanka reveals that the nation is very strong and healthy at all times, with maintaining a spirit of traditional life style and self-sufficient economy. Though, today a society becomes complex and the life style is deteriorating due to various health hazards such as communicable diseases and non-communicable diseases. The Chronic Kidney Disease of unknown etiology $(\mathrm{CKDu})$ is one of the major non-communicable diseases in health sector that is prevalent in North Central, Uva, North Western, North, Central and Eastern Provinces of Sri Lanka [1]. In addition, some of the CKDu cases have been recorded in Hambanthota district of Southern Province (Figure 1). The significant root for the CKDu has not yet been recognized [2]. However, it is believed

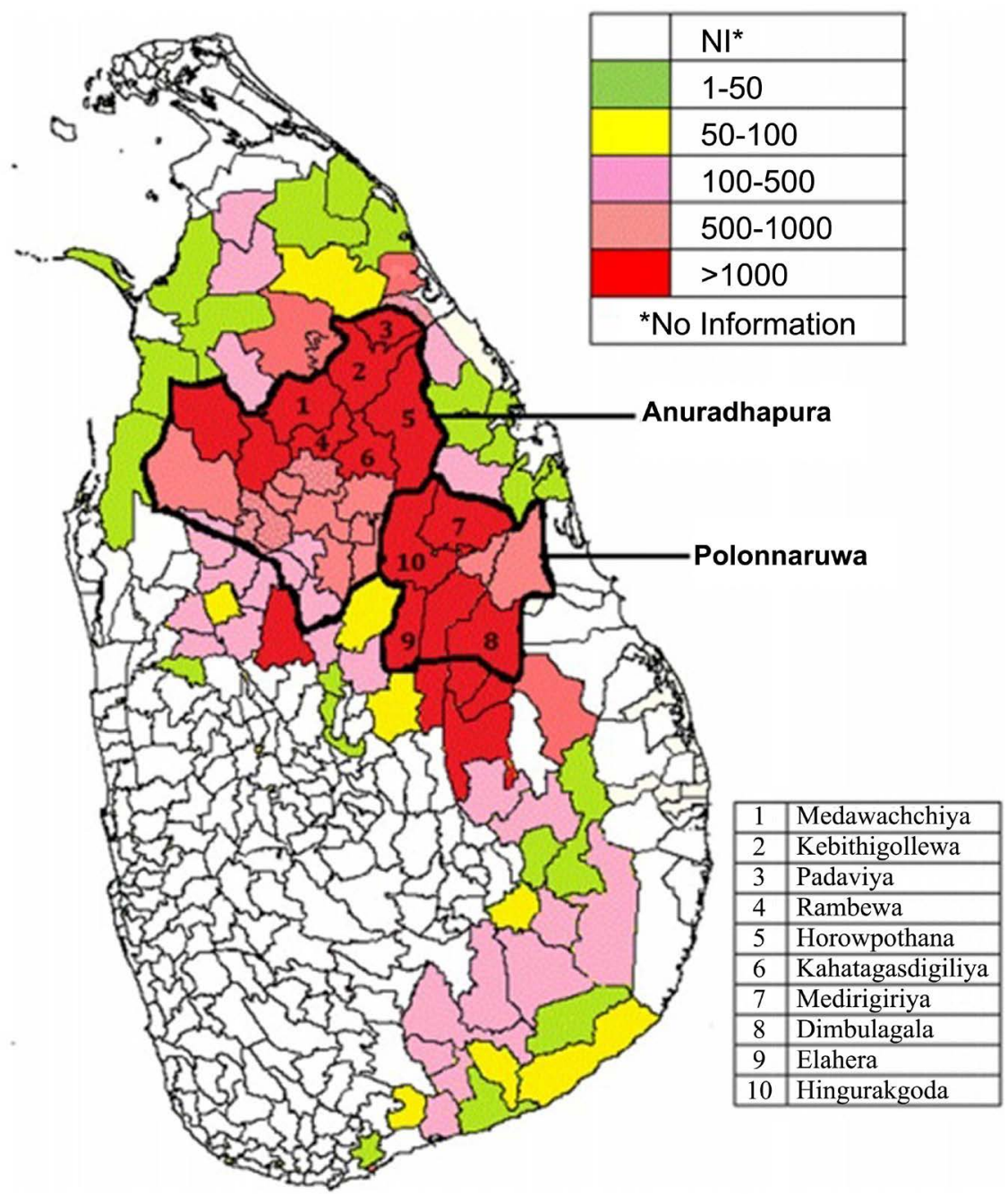

Figure 1. Chronic kidney disease of unknown etiology impacted areas. (lankaweb.com, 2016). 
that changes in certain number of drinking water quality parameters due to contamination of water sources by agricultural activities can be one of the roots for the CKDu [3]. Thus, the government of Sri Lanka realized the importance of supplying safe drinking water as an appropriate method to curtail the spread of the disease.

Brackish Water Reverse Osmosis (BWRO) is an advanced water filtration method which utilizes for purification of brackish water into safe drinking water. The wide-ranging BWRO plants are encompassed with pre-treatment process, membrane filtration technique, post treatment process and cleaning cycle to provide safe drinking water. At present 1800 electrically driven BWRO plants with an individual capacity of 10 tons per day (10 TPD) have been established in CKDu impacted villages to supply safe drinking water by Sri Lanka Navy (SLN) and National Water Board, Sri Lanka. However, a major drawback of these existing BWRO plants is that the recovery ratio of purified water is limited to $50 \%$ and it is insufficient as compared to availability of ground water yield at a dry zone of the country. Further, distribution of safe drinking water is restricted to 20 liters per day per family and therefore, in some cases they may have to walk longer distance to access the BWRO water. Moreover, a smaller version of domestic use electrically driven BWRO plant was also introduced to the rural farmer community for their domestic use. However, it did not practically work out due to various reasons such as high cost, unavailability of electrical power supply for those villages [4].

Energy consumption is one of the major cost components of existing BWRO purification processes. Therefore, a wide variety of experimental investigations have been carried out during this study to introduce renewable energy based BWRO applications to eliminate the dependence on fossil fuels and simultaneously to reduce the operational cost [5].

\section{Methodology}

This study is comprised of four major components which include assessment of the water consumption by $\mathrm{CKDu}$ impacted community and cost, calculation of manufacturing and maintaining the cost of hand pump integrated air operated domestic use BWRO plant (Figure 2), electrically driven BWRO plant with capacity of 10 tones/day (Figure 3(a)), and electrically driven domestic use BWRO (Figure 3(b)).

\subsection{Designing of an Air Operated Domestic Brackish Water Reverse Osmosis Plant (AO-BWRO)}

This prototype AO-BWRO plant is comprised of carbon filter, sand filter, cartridge filter, membrane, stock tank, gate valves, non-return valve, tap and pressure gauge. In addition, the AO-BWRO system is encompassed with a specially made raw water tank with a capacity of $25 \mathrm{~L}$ that is pressurized by a hand operated air pump. The experiments were conducted at the ambient temperature of $35^{\circ} \mathrm{C}$ with a fully operational mode to produce safe drinking water. The AO-BWRO 


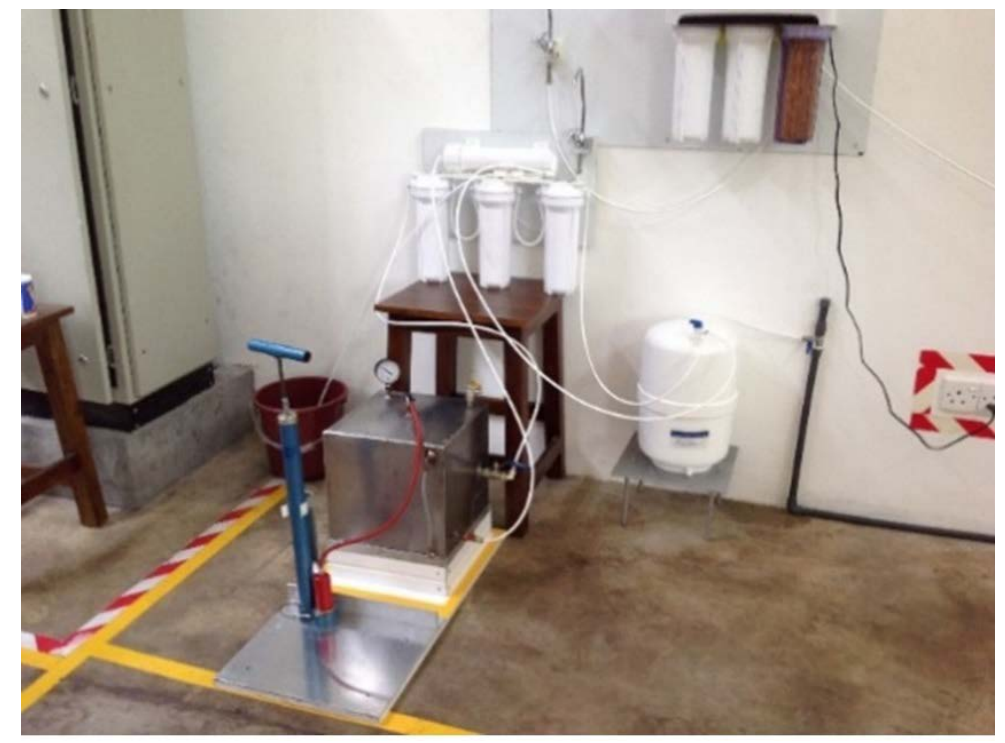

Figure 2. Air operated domestic use brackish water reverse osmosis plant.
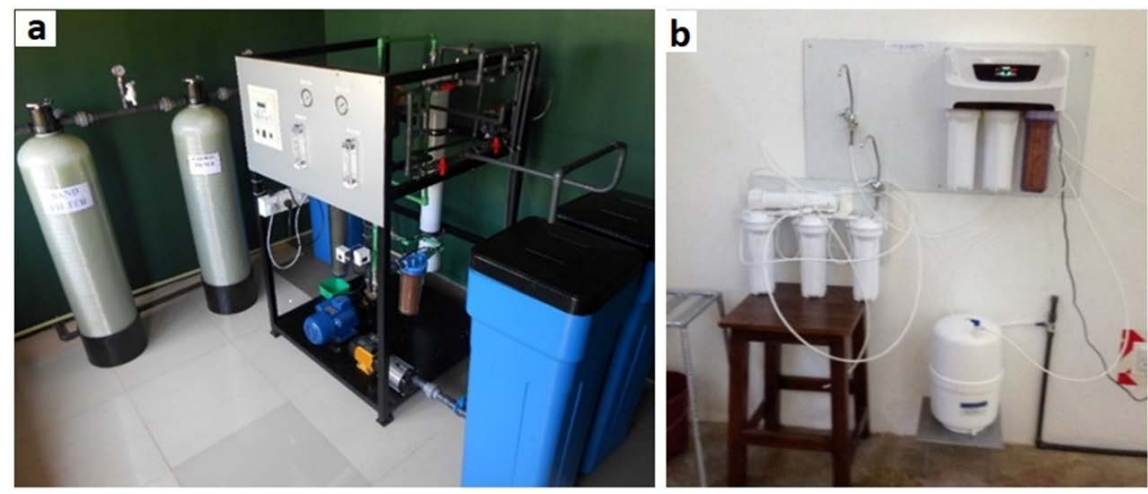

Figure 3. (a) Electrically driven brackish water reverse osmosis plant (10 TPD), (b) Domestic use electrically driven brackish water reverse osmosis plant installed in KDU.

system was comprehended with poly vinyl chloride (PVC) flexible pipes which is able to sustain with 10 bar pressure. A separate stock tank with a $7 \mathrm{~L}$ capacity was fixed to the newly designed AO-BWRO system for the storage of purified water. A flow restrictor was incorporated with the BWRO membrane to optimize the system pressure. A stainless-steel tap was amalgamated with stock tank by PVC flexible pipes (Figure 2).

\subsection{Operational Procedure of the AO-BWRO}

According to Figure 4, all gate valves should be closed except the filling valve no 1 to ensure the feed water flow through the cartridge filter, sand filter and carbon filter finally to fill the newly designed raw water tank no 6 with a maximum $20 \mathrm{~L}$ of water as in the first step. A conventional pretreatment procedure was adopted to this filtration system and maintained less than 1 bar pressure during feed water operation. Then, all the filling valves of raw water tank were closed and only the air filling valve no 9 was kept open. Air pumping up 


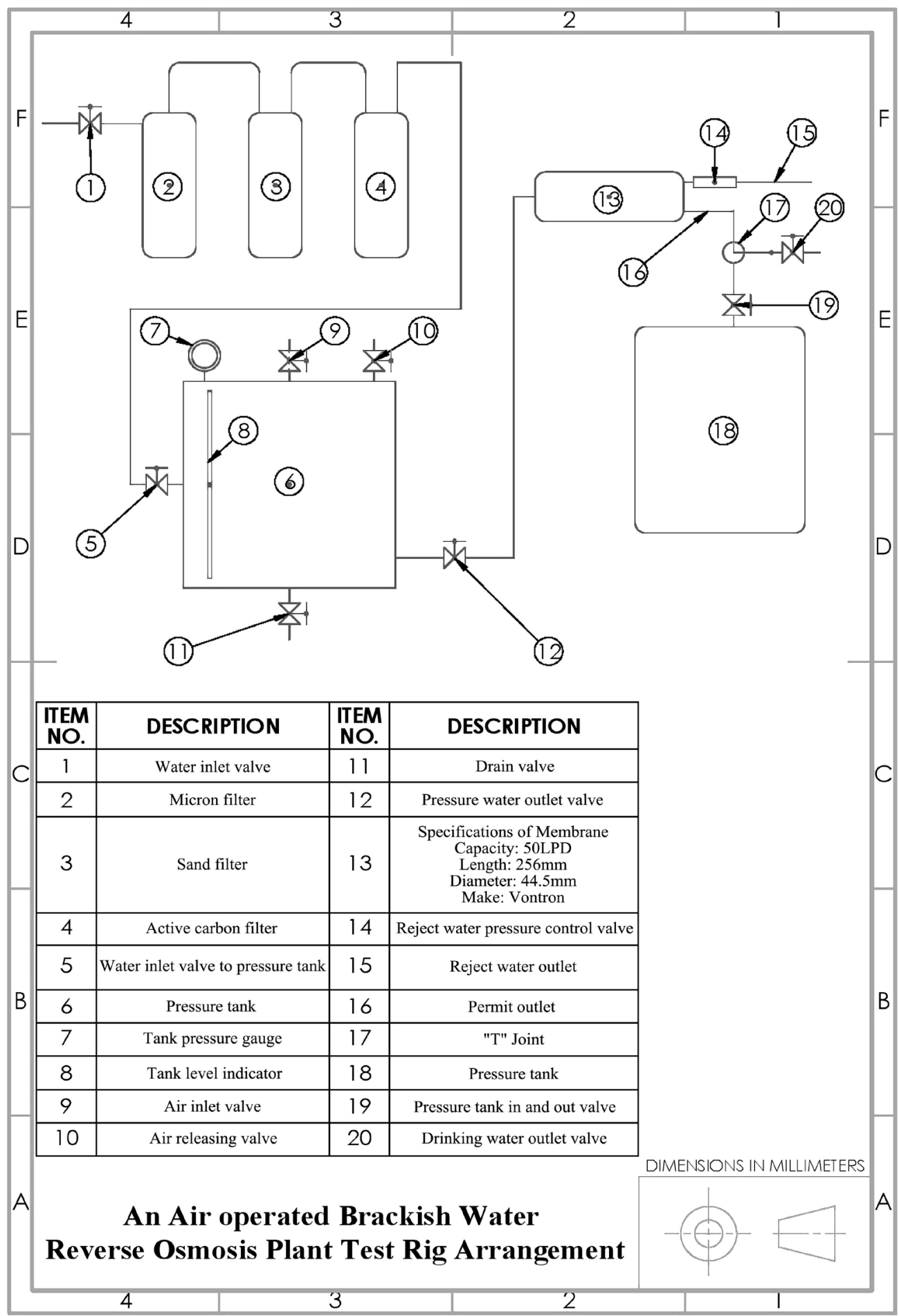

Figure 4. Schematic of air operated BWRO plant.

to 4 bar was done by the hand pump. Subsequently, the outlet valves no 12 of pressure tank was opened to allow the feed water to flow through a membrane to stock tank. Finally, safe drinking water can be accessed through a separate tap. In this experiment, a number of feed water samples were tested through this novel AO-BWRO plant. The obtained outcome of the drinking water quality was 
met with Sri Lanka Standards (SLS) requirements. This air operated domestic BWRO plant is sufficed with a capacity of $50 \mathrm{~L}$ per day.

\subsection{Cost Analysis}

The comprehensive cost and financial analyses were carried out based on the net present value (NPV), simple payback period (SPP), and internal rate of return (IRR) of the project.

$$
\mathrm{NPV}=\sum_{t=0}^{n} \frac{R_{t}}{(1+i)^{t}}
$$

where, $R_{t}$-Net cash inflow-outflow during single period $t$;

$i$-discount rate or return that could be earned per unit of time on an investment with similar risk;

$t$-number of time periods.

\section{Results}

Feasibility and benefits of the novel AO-BWRO design were evaluated base on the following criteria; cost for manufacturing and shelter, maintenance, water recovery ratio, cost for product water, simple payback period. The cost of product water from all three BWRO plants was calculated and compared to recognize the viability of the proposed AO-BWRO system for the rural community in $\mathrm{CKDu}$ impacted areas for the supply of safe drinking water to combat disease prevalence. Results of the cost analysis showed that AO-BWRO plant has low cost for the manufacturing the plant, cost of product water and shorter SPP as compared to that of Electrically driven BERO plant with the similar capacity of annual water consumption (Table 1 ).

Quality of seven major parameters in water samples obtained from 10 TPD BWRO Plant, electrically driven BWRO Plant and AO-BWRO plant were analysed based on SLS 614. Results of water quality parameters of water samples from 10 TPD Electrically BWRO Plant and electrically driven domestic use BWRO Plant are presented in Table 2 and Table 3 respectively.

Results of the water quality parameters of product water sample obtained from AO-BWRO Plant are given in Table 4. Further, three types of BWRO plants

Table 1. Comparison of the cost for manufacturing and maintenance of three different brackish water reverse osmosis (BWRO) plants.

\begin{tabular}{|c|c|c|c|c|c|c|c|}
\hline $\begin{array}{c}\text { Types of BWRO } \\
\text { plant }\end{array}$ & $\begin{array}{l}\text { Manufacturing } \\
\text { cost and shelter } \\
\text { cost (US\$) }\end{array}$ & $\begin{array}{l}\text { Annual maintain } \\
\text { cost (US\$) }\end{array}$ & $\begin{array}{l}\text { Annual electrical } \\
\text { power consumption } \\
\text { cost (US\$) }\end{array}$ & $\begin{array}{l}\text { Product water } \\
\text { recovery }\end{array}$ & $\begin{array}{c}\text { Annual water } \\
\text { consumption }(\mathrm{L})\end{array}$ & $\begin{array}{l}\text { Cost for product } \\
\text { water (L) (US\$) }\end{array}$ & SPP (Yrs) \\
\hline $\begin{array}{l}\text { Smaller version } \\
\text { electrically driven }\end{array}$ & 215 & 40 & 60 & $55 \%$ & 10950 & 0.029 & 4.5 \\
\hline Air operated & 100 & 40 & 0 & $55 \%$ & 10950 & 0.013 & 2.5 \\
\hline
\end{tabular}

SPP: simple payback period. 
Table 2. Evaluation of water quality parameters in product water of brackish water reverse osmosis plant (10 Ton/day).

\begin{tabular}{cccccc}
\hline Parameters & Feed water & $\begin{array}{c}\text { Product water } \\
\text { (Permeate) at } 3 \text { bar }\end{array}$ & $\begin{array}{c}\text { Permeate } \\
\text { at } 5.0 \text { bar }\end{array}$ & $\begin{array}{c}\text { Permeate } \\
\text { at } 8 \text { bar }\end{array}$ & $\begin{array}{c}\text { Standard value for } \\
\text { safe drinking water }\end{array}$ \\
\hline $\mathrm{pH}$ & 7.5 & 7.0 & 7.0 & 7.0 & $6.5-8.5$ \\
$\begin{array}{c}\text { Electrical conductivity } \\
(\mu \mathrm{S} / \mathrm{cm})\end{array}$ & 707 & 90 & 65 & 28 & 500 \\
$\mathrm{TDS}(\mathrm{mg} / \mathrm{L})$ & 707 & 90 & 65 & 28 & 500 \\
$\begin{array}{c}\text { Turbidity }(\mathrm{NTU}) \\
\text { Total hardness }(\mathrm{mg} / \mathrm{L} \\
\mathrm{CaCO})\end{array}$ & 1 & 1 & 1 & 1 & $2(\mathrm{Max})$ \\
$\mathrm{Ca}^{2+}(\mathrm{mg} / \mathrm{L})$ & 703 & 106 & 58 & 42 & 250 \\
$\mathrm{Mg}^{2+}(\mathrm{mg} / \mathrm{L})$ & 50 & 60 & 32 & 32 & 100 \\
\hline
\end{tabular}

Table 3. Evaluation of water quality parameters in product water of electrically driven brackish water reverse osmosis plant.

\begin{tabular}{cccccc}
\hline Parameters & $\begin{array}{c}\text { Feed } \\
\text { water }\end{array}$ & $\begin{array}{c}\text { Permeate } \\
\text { at } 2 \text { bar }\end{array}$ & $\begin{array}{c}\text { Permeate } \\
\text { at } 3.0 \text { bar }\end{array}$ & $\begin{array}{c}\text { Permeate } \\
\text { at 3.5 bar }\end{array}$ & $\begin{array}{c}\text { Standard value for } \\
\text { safe drinking water }\end{array}$ \\
\hline $\mathrm{pH}$ & 7.5 & 7.0 & 7.0 & 7.0 & $6.5-8.5$ \\
Electrical conductivity $(\mu \mathrm{S} / \mathrm{cm})$ & 707 & 112 & 46 & 46 & 500 \\
TDS (mg/L) & 707 & 112 & 46 & 46 & 500 \\
Turbidity (NTU) & 1 & 1 & 1 & 1 & $2(\mathrm{Max})$ \\
Total hardness (mg/L CaCO & & 11 & 250 \\
$\mathrm{Ca}^{2+}(\mathrm{mg} / \mathrm{L})$ & 403 & 140 & 65 & 65 & 100 \\
$\mathrm{Mg}^{2+}(\mathrm{mg} / \mathrm{L})$ & 78 & 78 & 48 & 48 & 30 \\
\hline
\end{tabular}

Table 4. Evaluation of water quality parameters of in product water from air operated brackish water reverse osmosis plant.

\begin{tabular}{cccccc}
\hline Parameters & $\begin{array}{c}\text { Feed } \\
\text { water }\end{array}$ & $\begin{array}{c}\text { Permeate } \\
\text { at 2 bar }\end{array}$ & $\begin{array}{c}\text { Permeate } \\
\text { at 3.0 bar }\end{array}$ & $\begin{array}{c}\text { Permeate } \\
\text { at 3.5 bar }\end{array}$ & $\begin{array}{c}\text { Standard value for } \\
\text { safe drinking water }\end{array}$ \\
\hline pH & 7.5 & 7.0 & 7.0 & 7.0 & $6.5-8.5$ \\
Electrical conductivity $(\mu \mathrm{S} / \mathrm{cm})$ & 707 & 112 & 46 & 46 & 500 \\
TDS $(\mathrm{mg} / \mathrm{L})$ & 707 & 112 & 46 & 46 & 500 \\
Turbidity $(\mathrm{NTU})$ & 1 & 1 & 1 & 1 & $2(\mathrm{Max})$ \\
Total hardness $(\mathrm{mg} / \mathrm{L} \mathrm{CaCO})$ & 403 & 140 & 65 & 65 & 250 \\
$\mathrm{Ca}^{2+}(\mathrm{mg} / \mathrm{L})$ & 78 & 78 & 48 & 48 & 100 \\
$\mathrm{Mg}^{2+}(\mathrm{mg} / \mathrm{L})$ & 50 & 28 & 23 & 18 & 30 \\
\hline
\end{tabular}

are compared in terms of power consumption (Table 5). Results of the comparison showed that approximately $3.72 \mathrm{KW}$ power is required to operate 10 TPD-BWRO while electrical driven BWRO needs $40 \mathrm{~W}$. However, the newly designed air-operated BWRO plant consumed zero electricity which also leads to the drastic reduction in Greenhouse Gas (GHG emission). 
Table 5. Comparison of pump capacities in three different brackish water reverse osmosis (BWRO) plant.

\begin{tabular}{cccc}
\hline Major Components & $\begin{array}{c}\text { 10 Tons/day } \\
\text { BWRO Plant }\end{array}$ & $\begin{array}{c}\text { Electrical Driven } \\
\text { BWRO Plant }\end{array}$ & $\begin{array}{c}\text { Air Operated } \\
\text { BWRO Plant }\end{array}$ \\
\hline High pressure pump & $2.22 \mathrm{KW}$ & $40 \mathrm{~W}$ & \\
Feed pump & $0.75 \mathrm{KW}$ & & \\
Dosing pump & $0.75 \mathrm{KW}$ & Manual operation \\
Hand pump & & & \\
\hline
\end{tabular}

Time taken to generate purified water in each BWRO plant was compared and results were shown in Table 6. In this electrically driven pump integrated BWRO plant operations, a fixed recovery $(7 \mathrm{~L})$ was stored at stock tank and measured the time by clock. Subsequently, rejected water was collected in a $20 \mathrm{~L}$ Can and measured by one-litter bottle. This process was carried out on four separate occasions with four different feed water samples. Then, an air-operated BWRO plant was operated in similar manner and gathered data in Table 6.

\section{Discussion}

Deterioration of water quality parameters is believed to be significantly contributing to the prevailing CKDu in North Central, Uva, North Western, North, Central, Eastern Provinces and Hambanthota District of Sri Lanka [1]. Hence, supply of safe drinking water is one of the major concerns to eliminate the $\mathrm{CKDu}$ from those affected areas. Currently, 10TPD electrically driven BWRO plants are used to provide safe drinking water. However, high power consumption is the main drawback of the use of this application [6]. In addition, beneficiaries have to walk a longer distance to access safe drinking water as the 10 TPD BWRO plant is set up in a central location in each village. Installation of several smaller versions of electrically driven BWRO plants was also attempted, but due to high initial \& maintenance cost, and the unavailability of power supply in rural areas, the mission was unsuccessful. Therefore, this study reports a novel design of domestic use AO-BWRO plant to overcome the above-mentioned drawbacks.

As shown in Table 1, the manufacturing cost of domestic use AO-BWRO is very less compared to the other two applications. Further, the annual maintenance cost of this domestic use AO-BWRO plant was very low and zero power consumption due hand operated air pump. The water recovery is slightly improved in domestic use AO-BWRO plant due to optimization of the flow restrictor during reject water management process. Moreover, a product water cost and SPP of domestic use AO-BWRO plant is very low when compared to the other two BWRO techniques. Further, it has been shown that the AO-BWRO purification process was met with SLS 614 standards. Further, it was showed that the low operation pressures of 3 to 4 bar are sufficed to function smaller version of BWRO 
Table 6. Comparison of water input, recovery and time taken to fill the stock tank between electrically driven brackish water reverse osmosis (BWRO) plant and vs air operated BWRO plant.

\begin{tabular}{ccccccc}
\hline \multirow{2}{*}{$\begin{array}{c}\text { Types of BWRO } \\
\text { Plant }\end{array}$} & Water & Product water & \multicolumn{4}{c}{ Time taken to fill product water in stock tank } \\
\cline { 4 - 7 } & input (L) & recovery (L) & 1 & 2 & 3 & 4 \\
\hline $\begin{array}{c}\text { Electrically driven } \\
\text { Air operated }\end{array}$ & 10 & 5.5 & $39 \mathrm{~min} 40 \mathrm{~s}$ & $40 \mathrm{~min} 10 \mathrm{~s}$ & $39 \mathrm{~min} 55 \mathrm{~s}$ & $40 \mathrm{~min} 14 \mathrm{~s}$ \\
\hline
\end{tabular}

plants with membrane surface area of $0.0358 \mathrm{~m}^{2}$. In addition, there is no electricity used during this purification process. Furthermore, a newly designed domestic use AO-BWRO application was operated by hand air filling pump and therefore it contributed to the zero GHG emission to the environment. The efficiency of the domestic use AO-BWRO plants is almost equal to the domestic use electrically driven BWRO plant. However, hand operated air pumping technique cannot be applied to the large scale BWRO plant as it could not generate sufficient pressure.

\section{Conclusion}

The newly designed domestic use AO-BWRO plant is significantly reduced the government expenditures to subsidize the water purification cost up to $50 \%$ of the existing expenses. In addition, simple payback time was 2.5 years and the benefit-cost ratio to be more than 1 . Evaluating the performance with the conventional values, it comprehends with more sustainable and economically viable system compared to the current method of water purification. If the air operated domestic use BWRO plant is provided for every household in CKDu affected areas, approximately 7.2 MW capacity of electricity can be saved by removing 10 TPD BWRO plants in operation. Further, we can protect the environment by reducing the GHG emission. The new technology in renewable energy and an innovative plant design is validated, to greater use of BWRO plants to provide safe drinking water for villagers with affordable cost. The author believes this demonstrated system is the start of new era for future development of AO-BWRO plants to provide purified water for CKDu impacted community in Sri Lanka.

\section{Acknowledgements}

I would like to acknowledge Dr. Himali. S Jayasinhearchchi (General Sir John Kotelawala Defence University) for her guidance and kind assistance throughout this research project. I would like to thank Chief Petty Officer AMS Adikari (Sri Lanka Navy) for his support to set up the Prototype AO-BWRO plant.

\section{Conflicts of Interest}

The author declares no conflicts of interest regarding the publication of this paper. 


\section{References}

[1] Ranasinghe, A.V., Kumara, G.W.G.P., Karunarathna, R.H., De Silva, A.P., Sachintani, K.G.D., Gunawardena, J.M.C.N., Kumari, S.K.C.R., Sarjana, M.S.F., Chandraguptha, J.S. and De Silva, M.V.C. (2019) The Incidence, Prevalence and Trends of Chronic Kidney Disease and Chronic Kidney Disease of Uncertain Aetiology $(\mathrm{CKDu})$ in the North Central Province of Sri Lanka: An Analysis of 30,566 Patients. BMC Nephrology, 20, Article No. 338. https://doi.org/10.1186/s12882-019-1501-0

[2] Annual Review Report (2019) Minister of Health, Nutrition and Indigenous Medicine, Sri Lanka. http://www.health.gov.lk/moh

[3] Riswan, M. (2015) Contribution of Community Water Projects In Preventing Water Crisis. http://ir.lib.seu.ac.lk/bitstream/handle/123456789/2057

[4] Wanasinghe, W.C.S., Gunarathna, M.H.J.P., Herath, H.M.P.I.K. and Jayasinghe, G.Y. (2018) Drinking Water Quality on Chronic Kidney Disease of Unknown Aetiology $(\mathrm{CKDu})$ in Ulagalla Cascade, Sri Lanka. Sabaragamuwa University Journal, 16, 17-27. https://doi.org/10.4038/suslj.v16i1.7714

[5] Stover, R.L. (2013) Industrial and Brackish Water Treatment with Closed Circuit Reverse Osmosis. Desalination and Water Treatment, 51, 1124-1130. https://doi.org/10.1080/19443994.2012.699341

[6] Guirguis, M.J. (2011) Energy Recovery Devices in Seawater Reverse Osmosis Desalination Plants with Emphasis on Efficiency and Economical Analysis of Isobaric versus Centrifugal Devices. Graduate Theses and Dissertations.

http://scholarcommons.usf.edu/etd/3135 